\title{
Transcatheter closure of an atrial septal defect with high risk of erosion using a Figulla Flex II atrial septal defect occluder
}

\author{
Norio Tada ${ }^{1}\left[\right.$ Yukiko Mizutani $^{1} \cdot$ Takashi Matsumoto $^{1} \cdot$ Mie Sakurai $^{1} \cdot$ \\ Tatsushi Ootomo
}

Received: 16 September 2016/ Accepted: 10 January 2017/Published online: 20 January 2017

(C) The Author(s) 2017. This article is published with open access at Springerlink.com

\begin{abstract}
An 85-year-old man with a high risk for open heart surgery underwent a percutaneous closure of an atrial septal defect that lacked adequate aortic and superior rims. To avoid the risk for erosion, a Figulla Flex II ASD occluder was selected for the procedure. Implantation was successful, and no complications were observed during the 6 months of follow-up.
\end{abstract}

Keywords Atrial septal defect · Figulla Flex II ASD occluder

\section{Introduction}

The Amplatzer septal occluder (ASO) is the most widely used device in the transcatheter closure of atrial septal defects (ASDs). Cardiac erosion is a rare; however, severe complications occur in $0.2 \%$ of patients $[1,2]$. The risk for erosion has been associated with oversized devices and an inadequate aortic rim [2]. Because the Figulla Flex II ASD occluder (FFO, Occlutech GmbH, Jena, Germany) disc has a softer edge compared with other devices, it may reduce the risk for erosion. We present a case of transcatheter ASD closure using FFO in a patient with a high morphological risk for erosion.

Norio Tada

noriotada@hotmail.com

1 Department of Cardiology, Sendai Kousei Hospital, 4-15 Hirosemachi, Aoba, Sendai, Miyagi 980-0873, Japan

\section{Case}

An 85-year-old man with a history of recurrent hospitalization because of congestive heart failure with pulmonary hypertension, chronic atrial fibrillation, and chronic kidney disease was referred to our hospital for ASD closure. Transthoracic echocardiography (TTE) confirmed a secundum ASD, right ventricular enlargement, and calculated shunt ratio $\left(Q_{\mathrm{p}} / Q_{\mathrm{s}}\right)$ of 1.8. Transesophageal echocardiography (TEE) was performed for a morphological assessment (Fig. 1). The maximum diameter of the defect was $24.1 \mathrm{~mm}$ at $30^{\circ}$, and the minimum diameter of the defect was $18.2 \mathrm{~mm}$ at $0^{\circ}$. The aortic rim was deficient at $30^{\circ}-60^{\circ}$, and the superior rim was deficient at $60^{\circ}-90^{\circ}$. The posterior rim was not floppy and was sufficiently long. Septal malalignment was observed at $60^{\circ}$ and $90^{\circ}$. We assessed the patient as being at a high risk for erosion or migration of the closure device because of rim deficiency and septal malalignment. He still complained of shortness of breath on exertion under medical treatment. Because his history also placed him at a high risk for open heart surgery, we chose to perform a transcatheter closure using FFO. Written informed consent was obtained from the patient and his family prior to the procedure.

\section{Procedure}

Percutaneous ASD closure was performed under TEE guidance. Balloon sizing was measured to be $27 \mathrm{~mm}$. The FFO size could be 27 or $30 \mathrm{~mm}$ because the maximum diameter of the defect was $24.1 \mathrm{~mm}$. Considering the oval shape with a minimum diameter of $18.2 \mathrm{~mm}$ and aortic and superior rim deficiency, we chose and deployed a 27-mm FFO (Fig. 2). A ball-shaped connector design allows a tilt 

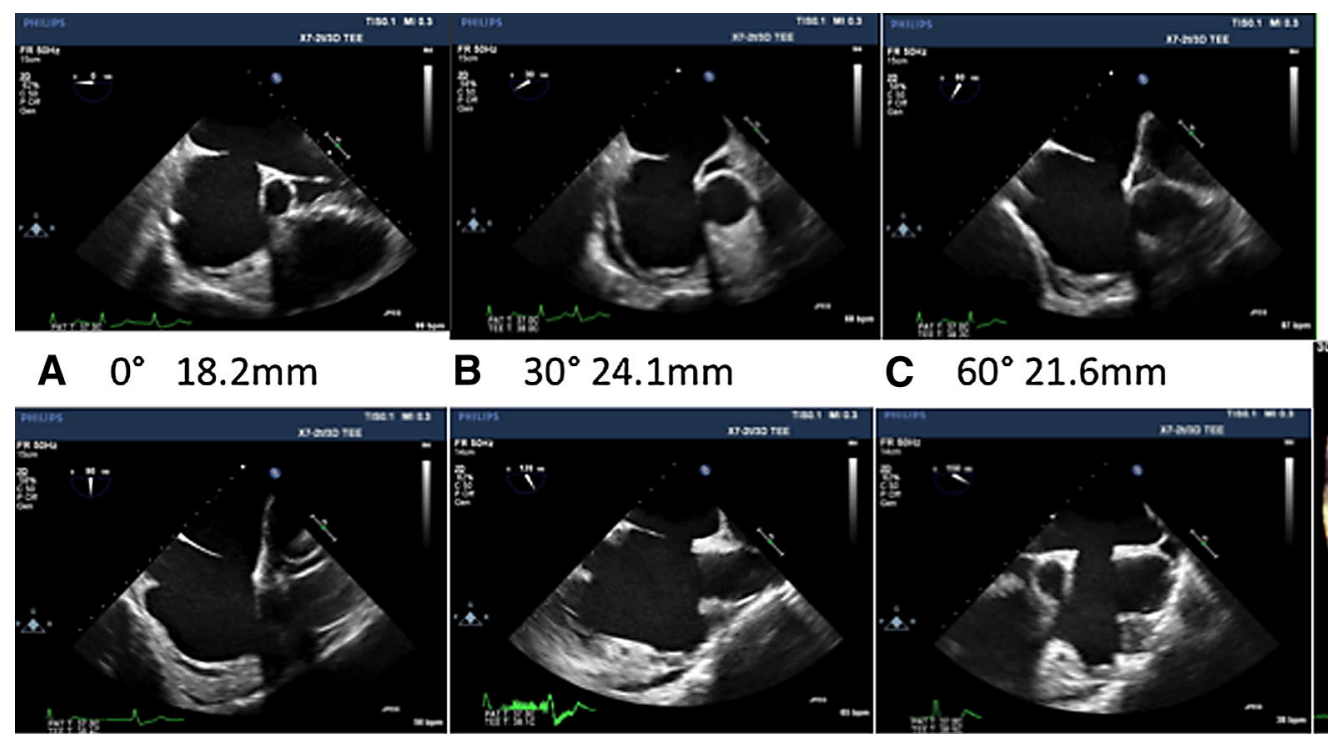

D $90^{\circ} 20.1 \mathrm{~mm}$

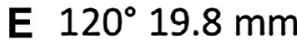

Fig. 1 Transesophageal echocardiography of the atrial septal defect. Two-dimensional images and defect diameters each at $30^{\circ}(\mathbf{a}-\mathbf{f})$ and a three-dimensional right atrial en-face view image (g) are shown. The maximum defect diameter was $24.1 \mathrm{~mm}$ at $30^{\circ}$, and the minimum

\section{C $60^{\circ} 21.6 \mathrm{~mm}$}

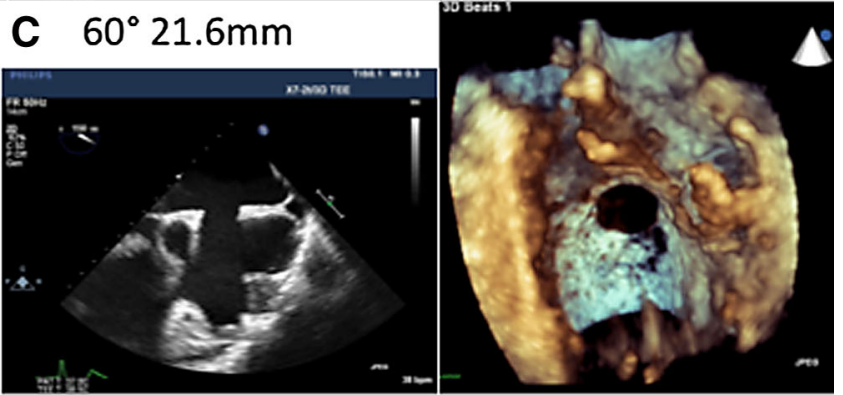

F $150^{\circ} 18.4 \mathrm{~mm}$

G
Fig. 2 Transesophageal echocardiographic image after deploying the Figulla Flex II ASD occluder. The cable remains connected. A ballshaped connector design allows a tilt of up to $50^{\circ}$, facilitating placement before release

of up to $50^{\circ}$, facilitating the assessment of deployment. After release, the device was stable and TEE at $30^{\circ}$ and $60^{\circ}$ views showed good device conformability with the misaligned septum and minimal left disc tenting of the atrial free wall into the transverse sinus (Fig. 3). The procedure was complete.

\section{Follow-up}

Patient recovery was uneventful with NYHA 1 during the 6 months of follow-up. TTE revealed adequate sandwiching of the septum and smooth contact with the sinus of Valsalva (Fig. 4). Pericardial effusion did not increase.

\section{Discussion}

Erosion is a rare but severe complication of transcatheter ASD closure [1, 2]. Aortic rim deficiency and implantation of an oversized device are risk factors for erosion [2]. Amin [3] reported that echocardiographic evidence of aortic rim absence in multiple views, poor posterior rim consistency, defect diameter was $18.2 \mathrm{~mm}$ at $0^{\circ}$. The aortic rim was deficient at $30^{\circ}-60^{\circ}$, and the superior rim was deficient at $60^{\circ}-90^{\circ}$. The posterior rim was not floppy and was sufficiently long. Septal malalignment was observed at $60^{\circ}$ and $90^{\circ}$

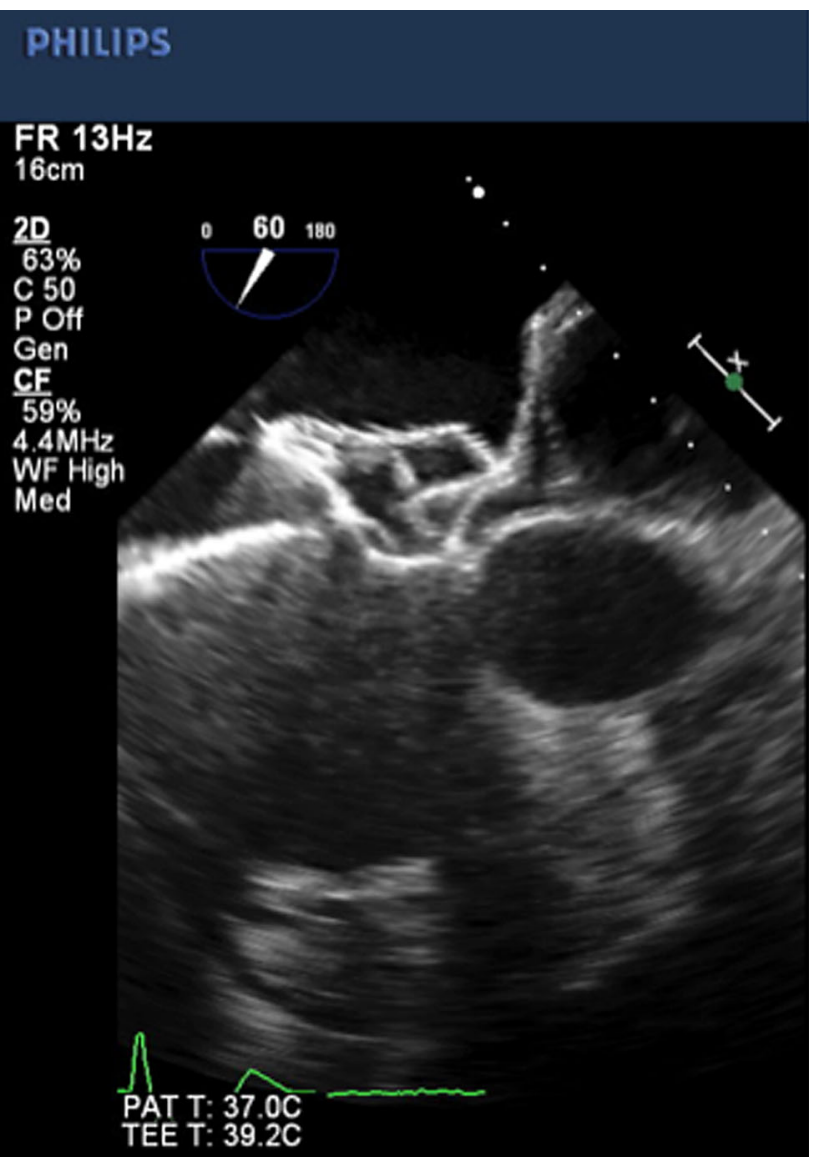



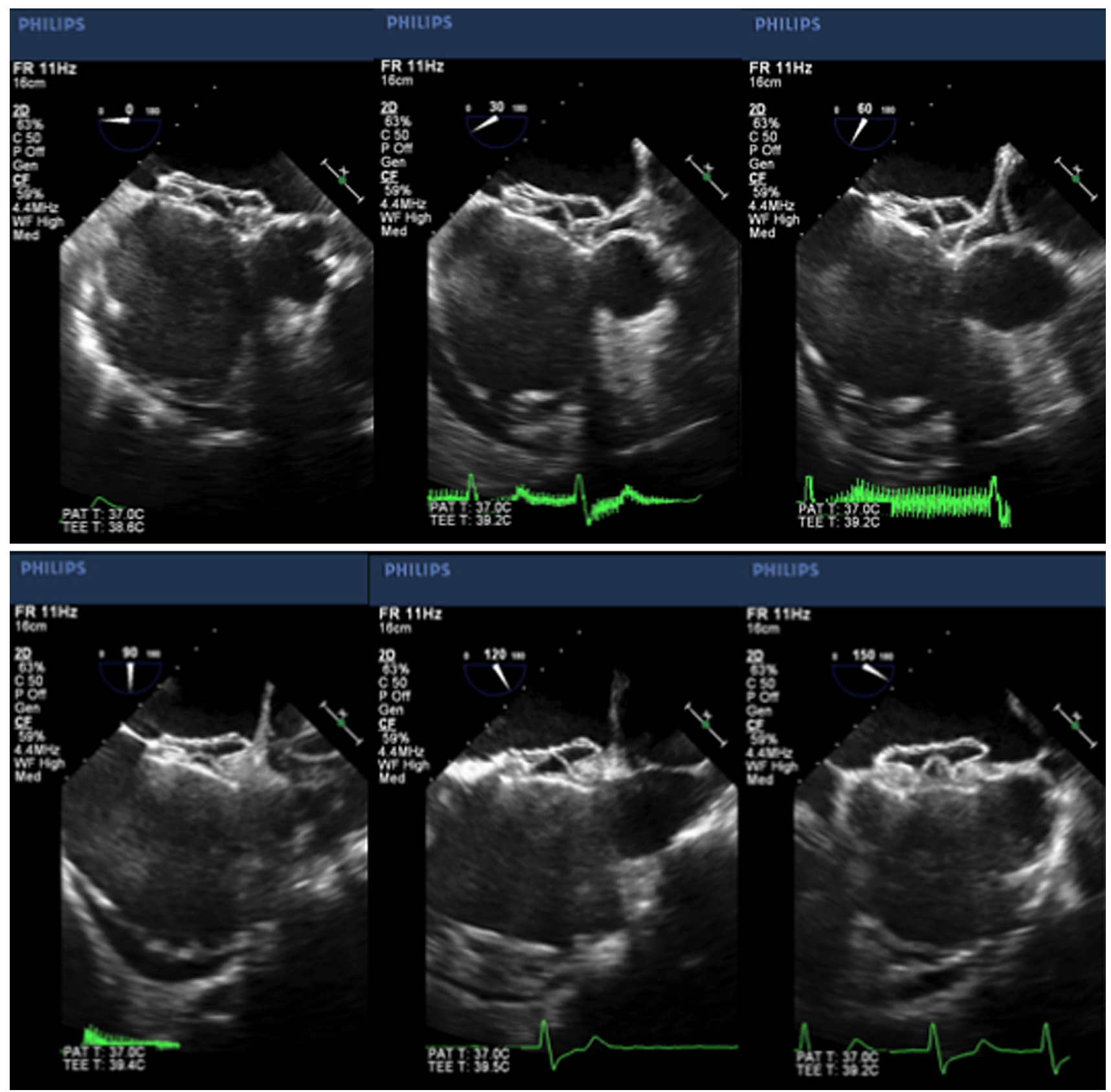

Fig. 3 Transesophageal echocardiographic (TEE) image after deploying the Figulla Flex II ASD occluder. The device was stable, and TEE at $30^{\circ}$ and $60^{\circ}$ views showed good device conformability

septal malalignment, and dynamic changes in ASD indicated an increased risk for erosion. Evidence of device tenting of the atrial free wall into the transverse sinus, as in this case, was also a risk factor [3]. The morphological characteristics of this patient were consequently indicated as a high risk for erosion using ASO.

FFO is a double-disc occluder that is similar to ASO, but its left disc utilizes a unique braiding system without a hub, reducing the amount of material and giving it a lower profile than ASO. This construction results in a softer with the malaligned septum and minimal left disc tenting of the atrial free wall into the transverse sinus

contact with aortic vessel walls if placed adjacent to it [4]. Erosion has not yet been reported in cases wherein FFO was used [4-6]. Haas et al. [4] reported a registry of Occlutech device use for 1315 patients. There were no cases of erosion in the registry. According to device embolization, $1.1 \%$ occurred during implantation and $0.4 \%$ during follow-up. Most defects had no rim, and they clearly demonstrated an increased risk for device embolization when balloon sizing was not performed. Therefore, we still require discussions regarding the interaction differences of 


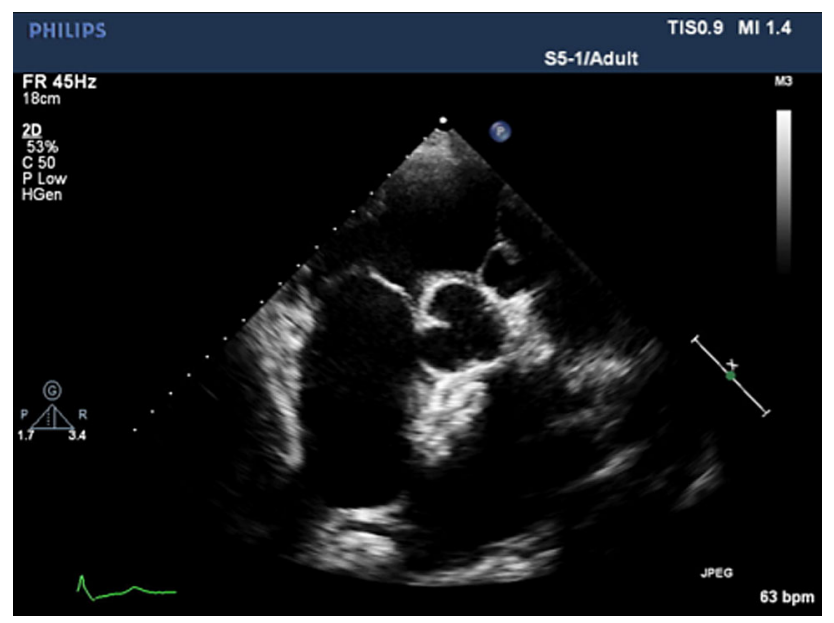

Fig. 4 Transthoracic echocardiographic short axis view after 6 months of follow-up. The device contacts the sinus of Valsalva smoothly, and the pericardial effusion has not increased

devices and the risk for embolization. However, during deployment, the left atrial portion has a round, ball-like shape unlike the flat profile of devices with a double-sided hub. This prevents a prolapse of the left disc during implantation, particularly in large ASDs, those without a rim, or those with a minimal aortic rim [5].

Six months after the procedure, the patient had not experienced any complications. Because a late occurrence of erosion or migration has been reported with ASO, we need to continue close follow-up [7-9]. FFO may be a solution for patients with a morphologically high risk for transcatheter ASD occlusion.

\section{Compliance with ethical standards}

Conflict of interest We have no conflicts of interest or human and/or animal rights statement to declare.

Open Access This article is distributed under the terms of the Creative Commons Attribution 4.0 International License (http://crea tivecommons.org/licenses/by/4.0/), which permits unrestricted use, distribution, and reproduction in any medium, provided you give appropriate credit to the original author(s) and the source, provide a link to the Creative Commons license, and indicate if changes were made.

\section{References}

1. Crawford GB, Brindis RG, Krucoff MW, Mansalis BP, Carroll JD. Percutaneous atrial septal occluder devices and cardiac erosion: a review of the literature. Catheter Cardiovasc Interv. 2012;80: 157-67.

2. Amin Z, Hijazi ZM, Bass JL, Cheatham JP, Hellenbrand WE, Kleinman CS. Erosion of Amplatzer septal occluder device after closure of secundum atrial septal defects: review of registry of complications and recommendations to minimize future risk. Catheter Cardiovasc Interv. 2004;63:496-502.

3. Amin Z. Echocardiographic predictors of cardiac erosion after Amplatzer septal occluder placement. Catheter Cardiovasc Interv. 2014;83:84-92.

4. Haas NA, Soetemann DB, Ates I, Baspinar O, Ditkivskyy I, Duke $\mathrm{C}$, et al. Closure of secundum atrial septal defects by using the Occlutech occluder devices in more than 1300 patients: the IRFACODE Project: a retrospective case series. Catheter Cardiovasc Interv. 2016. doi:10.1002/ccd.26497.

5. Haas NA, Happel CM, Soetemann DB, Hanslik A, Moysich A, Kececioglu D, et al. Optimal septum alignment of the Figulla Flex occluder to the atrial septum in patients with ASDs. Euro Interv. 2016;11:1153-60.

6. Godart F, Houeijeh A, Recher M, Francart C, Polge A-S, Richardson M, et al. Transcatheter closure of atrial septal defect with the Figulla ${ }^{\circledR}$ ASD Occluder: a comparative study with the Amplatzer $^{\circledR}$ Septal Occluder. Arch Cardiovasc Dis. 2015;108: 57-63.

7. Taggart NW, Dearani JA, Hagler DJ. Late erosion of an Amplatzer septal occluder device 6 years after placement. J Thorac Cardiovasc Surg. 2011;142:221-2.

8. Roberts WT, Parmar J, Rajathurai T. Very late erosion of Amplatzer septal occluder device presenting as pericardial pain and effusion 8 years after placement. Catheter Cardiovasc Interv. 2013;82:592-4.

9. Lysitsas DN, Wrigley B, Banerjee P, Glennon PE, Parmar JM, Shiu MF, et al. Presentation of an embolised Amplatzer septal occluder to the main pulmonary artery 2 years after implantation. Int J Cardiol. 2009;131:e106-7 Epub 2007 Oct 18. 